\title{
Segmental Neurofibromatosis
}

\author{
Dimble Raju ${ }^{1}$ Nabanita Ghosh ${ }^{2}$ Sayan Das ${ }^{3}$ Prasad Krishnan ${ }^{3}$
}

${ }^{1}$ Department of Neurosurgery, National Neurosciences Centre, Calcutta, West Bengal, India

${ }^{2}$ Department of Neuroanesthesiology, National Neurosciences Centre, Calcutta, West Bengal, India

${ }^{3}$ Department of Radiology, Peerless Hospital and B K Roy Research Centre, Calcutta, West Bengal, India

J Neurosci Rural Pract 2021;12:441-442.

\begin{abstract}
Address for correspondence Prasad Krishnan, MS, MCh, Department of Neurosurgery, National Neurosciences Centre, Peerless Hospital Campus, 2nd Floor, 360, Panchasayar, Garia 700094, Kolkata, West Bengal, India (e-mail: prasad.krishnan@rediffmail.com).
\end{abstract}
Abstract
Keywords
- mosaicism
- neurofibromatosis
- sectorial neurofibromatosis
- segmental neurofibromatosis

Segmental neurofibromas are the rarest variant of neurofibromatosis. We describe one such case in a 34-year-old man with multiple subcutaneous swellings in the posterior aspect of the left lower limb.

\section{Introduction}

A 34-year-old male presented with multiple swellings in his left lower limb of several years duration some of which were progressively increasing in size. The swellings were only on

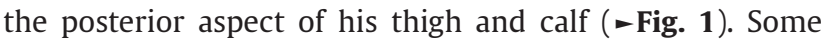
were tender and he had difficulty in sitting on hard surfaces. Magnetic resonance imaging (MRI) of the lower limbs revealed all of these to be subcutaneous with no deeper spread ( - Fig. 2). MRI of his spine and lumbar and sacral plexuses were normal. Excision biopsies of the largest ones were performed and reported as neurofibromas. Subsequently, investigations did not reveal any ocular or skeletal abnormalities or skin discolorations anywhere in the body, and further no family history for a similar disease was elicitable.

\section{Discussion}

Segmental neurofibromatosis (SNF) was first described by Crowe in 1956 and termed as sectorial neurofibromatosis. ${ }^{1}$ It was later renamed as SNF by Miller and Sparkes in 1977. ${ }^{1}$ While neurofibromatosis (NF) is among the commonest congenital diseases (1 in 3,000 births), ${ }^{2,3}$ SNF is extremely rare and its estimated prevalence is between 0.0014 and $0.002 \%{ }^{2,3}$ It is hypothesized to occur due to a postzygotic mutation of the NF1 gene late in the course of embryonic development affecting a subset of cells (localized neural crest lines) in the fetus rather than a germline NF1 gene mutation that would affect all cells in the body. ${ }^{4}$ As a consequence, the disease is localized (i.e., segmental) and further these mutations are detected only in cells in the affected region and not elsewhere in the body or in leucocytes in circulating blood as in most cases of NF.,5

SNF was initially classified as NF type $\mathrm{V}$ and was considered to have the following characteristics, skin changes or neurofibromas in a single, unilateral body part with no crossing of the midline and absence of family history and systemic involvement. ${ }^{3,6}$ However, rarely bilateral SNF has been noted (6\% cases) $)^{2,3}$ and patients with SNF have had children with systemic NF as well. ${ }^{3}$ This is explained by gonadal mosaicism. ${ }^{3,6}$ To resolve these discrepancies, Roth et $\mathrm{al}^{7}$ further classified SNF into four subtypes: true segmental, localized with deep involvement, hereditary, and bilateral. Clinically, SNFs may be divided into those with cutaneous markers alone, those with neurofibromas alone (most common) and those with cutaneous markers and neurofibromas, and those with plexiform neurofibromas. ${ }^{1-3,6}$
DOI https://doi.org/

10.1055/s-0040-1721197 ISSN 0976-3147. (c) 2021. Association for Helping Neurosurgical Sick People.

This is an open access article published by Thieme under the terms of the Creative Commons Attribution-NonDerivative-NonCommercial-License, permitting copying and reproduction so long as the original work is given appropriate credit. Contents may not be used for commercial purposes, or adapted, remixed, transformed or built upon. (https://creativecommons.org/licenses/by-nc-nd/4.0/)

Thieme Medical and Scientific Publishers Pvt. Ltd., A-12, 2nd Floor, Sector 2, Noida-201301 UP, India 

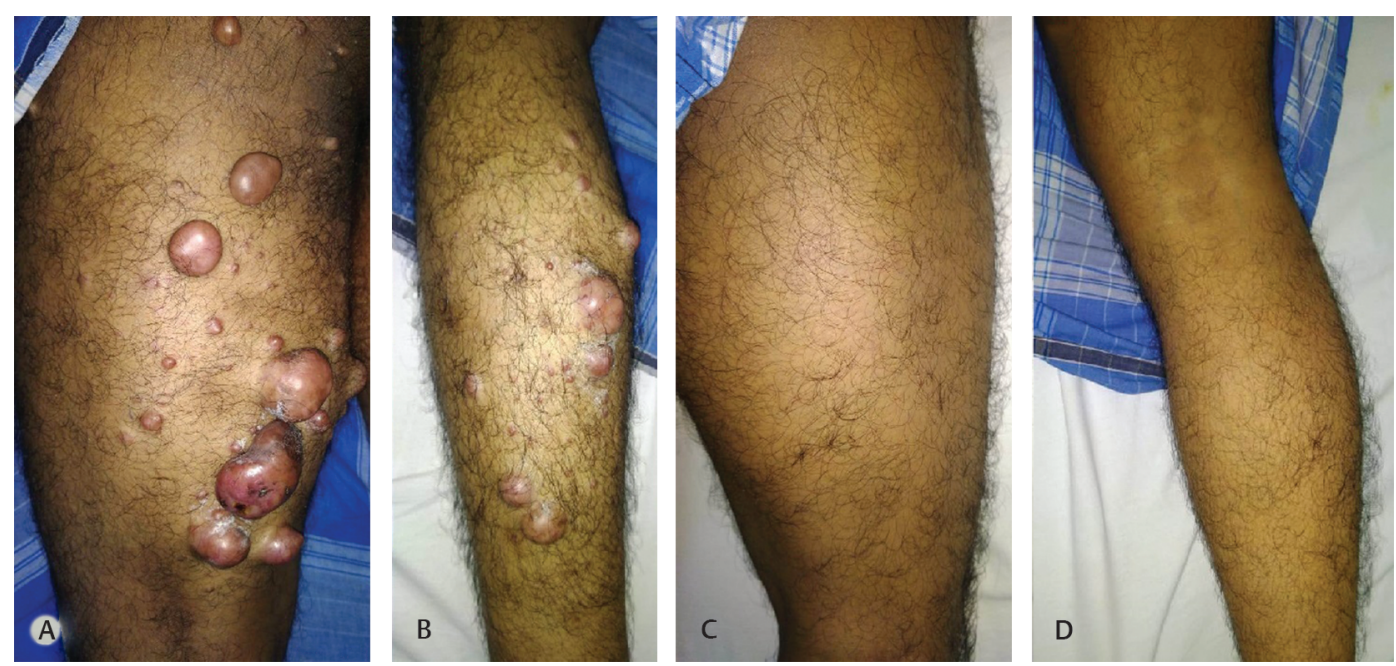

Fig. 1 Clinical photograph of (A) back of left thigh and (B) back of left leg of the patient showing multiple subcutaneous neurofibromas in contrast to (C) and (D) clinical photograph of back of right thigh and right lower leg which appear normal.
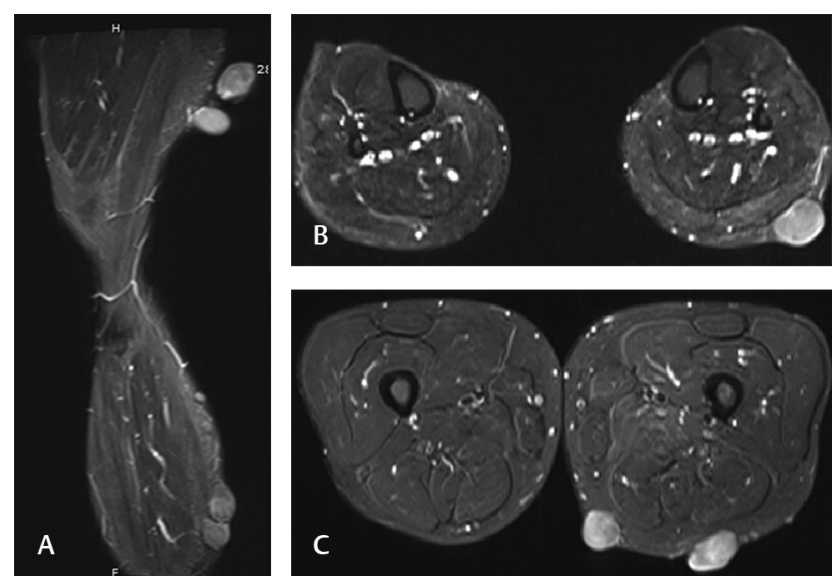

Fig. 2 Proton density fat saturated magnetic resonance imaging sequences (A) parasagittal left leg, (B) axial at level of both legs, and (C) axial at level of both thighs showing subcutaneous neurofibromas on the left side with no deeper involvement.

Differential diagnosis like nevus lipomatosus cutaneous superficialis, agminated lentiginosis (when only pigmentary skin changes are present), granuloma annulare, multiple fibromas, and eruptive xanthomas have been mentioned in literature ${ }^{6,8}$ but can easily be ruled out by histopathological diagnosis of an excised mass.

While there is no definitive treatment for SNF, large disfiguring and painful lesions can be treated by surgical excision.

\section{Funding}

None.

\section{Conflict of Interest}

None declared.

\section{References}

1 Gabhane SK, Kotwal MN, Bobhate SK. Segmental neurofibromatosis: a report of 3 cases. Indian J Dermatol 2010;55(1):105-108

2 Sobjanek M, Dobosz-Kawałko M, Michajłowski I, Pęksa R, Nowicki R. Segmental neurofibromatosis. Postepy Dermatol Alergol 2014;31(6):410-412

3 Victor FC. Segmental neurofibromatosis. Dermatol Online J 2005;11(4):20

4 Freret ME, Anastasaki C, Gutmann DH. Independent NF1 mutations underlie café-au-lait macule development in a woman with segmental NF1. Neurol Genet 2018;4(4):e261

5 Tinschert S, Naumann I, Stegmann E, et al. Segmental neurofibromatosis is caused by somatic mutation of the neurofibromatosis type 1 (NF1) gene. Eur J Hum Genet 2000;8(6):455-459

6 Doshi BR, Belgaumkar VA, Chougule NS. Intriguing bumps over palms and soles. Indian J Dermatol 2019;64(3):245-246

7 Roth RR, Martines R, James WD. Segmental neurofibromatosis. Arch Dermatol 1987;123(7):917-920

8 Kumar S, Kumar RP. Multi-segmental neurofibromatosis. Indian J Dermatol Venereol Leprol 2004;70(6):361-363 